\title{
EN LA RAIZ MEXICANA: \\ PETRIFICADA PETRIFICANTE DE OCTAVIO PAZ
}

POR

ALEJANDRO GONZALEZ ACOSTA

Universidad Nacional Autónoma de México

Este comentario intenta estudiar la referencialidad escindida de la poesía en "Petrificada petrificante" de Octavio Paz, perteneciente a su libro Vuelta (1975). Este poema ya lo había publicado antes su autor, con ligeras variantes, en el número 29 de la revista Plural, en septiembre de $1973^{1}$.

Como consecuencia de la referencialidad escindida, el lenguaje adquiere su función artística esencial que convierte el texto en una obra de arte. La relación que existe entre lo propiamente textual y lo intertextual con lo extratextual determina la tensión creativa del poema.

Después de una larga etapa de preceptiva, donde cada escuela, tendencia, estilo o método - como se los quiera llamar - ha tratado de imponer una sola interpretación posible del texto (con diferentes "ismos": sociologismo, historicismo, ideologismo, et al) la hermenéutica fenomenológica aplicada al terreno de los estudios literarios abre otra posiblidad de aceptar la validez de tantas lecturas de una obra como lectores efectivos tenga ésta, en función del carácter siempre abierto del producto artístico, que de esta manera se enriquece a sí mismo y también enriquece a cada lector sobre la base necesaria e insustituible del diálogo. Es a partir de estos principios básicos que pretendo abordar el comentario de un poema de los más grandes autores de la lírica contemporánea, "Petrificada petrificante", de Octavio Paz.

"Petrificada petrificante" cuenta con 167 líneas en verso libre; fue publicado por primera vez en la revista Plural, y más tarde, en versión "casi definitiva", en las Obras de Octavio Paz ${ }^{3}$ agrupadas en el volumen Poemas.

$\mathrm{El}$ análisis y comentario de "Petrificada petrificante" supone un verdadero tour de force por la complejidad del poema, su factura y profunda mexicanidad,

\footnotetext{
${ }^{1}$ Para la primera versión del poema", véase México, Plural 29( septiembre 1973): 5. Para la version "definitiva" véase Octavio Paz, Poemas (1935-1975) 2da. ed. Barcelona: Seix Barral, 1981.

2 El carácter "provisorio" de la poesía de Paz será analizado más adelante en este comentario.

${ }^{3}$ Aunque existía el propósito editorial de publicar la totalidad de la producción de Octavio Paz, hasta el momento sólo ha aparecido este volumen. Vid, Nota 1.
} 
sobre todo para el comentarista no mexicano, sobre todo, para quien no esté profundamente enterado de la cultura y la historia de México. Peroel propio Paz reconoce lo abierto de su producción poética, al señalar que un poema es "un objeto que es el producto de una práctica y no la consecuencia de un sistema"4, por lo cual "toca al lector, no a mi, descubrir si hay algo que no cambia en mis cambios"s.

En mi lectura de "Petrificada petrificante" aprecié tres divisiones estructurales del extenso poema: una primera, que llamé "Las raíces" (líneas 1-75); una segunda, "La transculturación" (líneas 76-125) y una tercera, "Tiempo de ira" (líneas 126-167). Por supuesto, estas divisiones solamente son grupos temáticos que he realizado arbritrariamente para facilitar el trabajo de introducir el instrumento de análisis en el cuerpo del poema, el cual constituye un todo homogéneo que el autor plantea como una continuidad histórica. Tienen, pues, un carácter provisional y nunca concluyente; es decir, en relación directa con mi lectura particular.

El poema comienza con una línea que es toda una metáfora, por la riqueza de sentidos que implica; "Terramuerta"; tierra-muerta, intención que se amplía y complementa en la línea siguiente con el epíteto de factura surrealista y ecos de César Vallejo: "terrisombra nopaltorio temezquible". Al parecer, se reiteran la oscuridad y la aridez como atributos de la tierra, que es, además, "cenipolva" (ceniza-polvo) y "pedrósea" (piedra-hueso) y se sintetiza en una contradicción: "fuego petrificado". Todo permanece detenido en esta tierra, como el día antes de la creación; el ciclo del agua se interrumpió (líneas 5-18). El viento se reitera paradójicamente como elemento de lo estático, en una tierra desértica, donde laten fuerzas ocultas ("la cama fría del fuego"). Sobre este panorama reina el sol, "anicorazol centrotal caledadoro". En esta suerte de "cadáver exquisito" identifico claves que da el autor para seguir su pensamiento: "corazón", "centro", "oro", todos conjugables con la imagen solar. Se produce entonces una especie de paralelismo aliterado en las líneas 24 y 25 entre vocablos como "cuento", "cuenta" y "canto", aplicado al decurso del tiempo, que desemboca en "chatarra", "pedregal", "arena" y "machacar", todo lo cual da idea y transmite la sensación de desgarramiento, golpes y destrucción. La servidumbre aparece en otro tropo surrealista (línea 30): "talomordaz afrenoboz alrronzal", donde pueden identificarse claves como "mordaz" (hiriente), "freno" y "ronzal", todos ellos elementos propios de la caballada sometida. La ruptura fratricida aparece ya, con directa alusión bíblica, cuando el poeta habla de "caídos caínes" y "abeles en jirones", sin mayúsculas distanciantes, estableciendo así un contrapunteo que se continúa en otros elementos aliterados: "sectarios sicarios", "ladinos ladrones" e "idólatras letrados", donde la presencia de una consonante fricativa como la " $r$ " produce la reiterada sensación de desgarramiento y ruptura. La

4 Octavio Paz, Op. cit., "Advertencia”, 12.

Idem, 13. 
alusión a la cultura náhuatl se aprecia también al hablar de los ladridos del "can tuerto, el guía de los muertos", que se refiere a Xólotl, el dios "doble" de Quetzalcóatl y en la definición de la ciudad de México como el "Ombligo de la luna" (metztli=luna, xictli=ombligo, co=lugar). La síntesis de toda esta parte del poema aparece en las líneas 40-56:

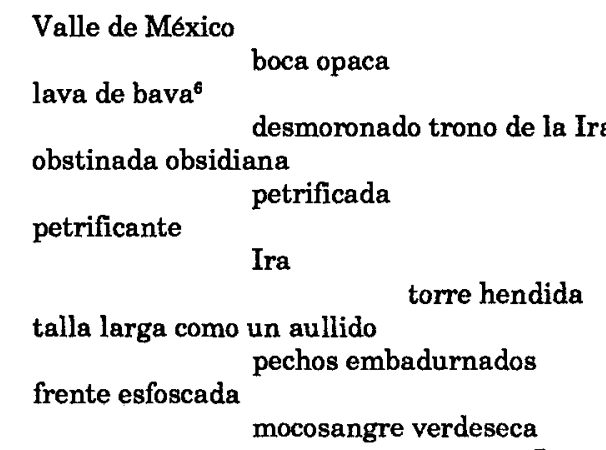

fijeza clavada en una herida

sobre un país de espinas y de púas.

Ira

Los elementos que denotan rigidez aparecen reiteradas veces en el fragmento aquí reproducido: Lava, obsidiana y sombra se encuentran rodeando la idea medular, "petrificada petrificante", es decir, una piedra que no sólo exite como tal, sino que, como otra versión del rey Midas, transforma todo cuanto la rodea en su propia esencia hierática y terrible, la que deriva en "aullidos", pinturas totémicas de guerra, mocos, sangre, navajas, herida y, sobre todo, en la Ira que gobierna sobre las espinas y las púas. Es casi la imagen de una crucifixión, que da paso a una letanía de epítetos encadenados, pero en lugar de "Turris ebúrnea, mater amantísima, Rosae misticae ... " se abre en las imágenes de la salmodia: "Circo de montes/teatro de las nubes/mesa del mediodía/estera de la luna/jardín de planetas/tambor de la lluvia/balcón de las brisas/ silla del sol”, todo lo cual da idea de quietud, pero prontamente conturbada por las imágenes reventadas y empaladas, manos cortadas, lenguas arrancadas, senos tronchados y vergas guillotinadas, que transmiten una sensación de violencia y desgarramiento en una máquina de tortura que funciona automáticamente con su "tristrás" inclemente y ciego, para podar el árbol de sangre, "el árbol inteligente" que, como en algún otro poema de Paz, se refiere al pensamiento, y en este caso, parece aludir a la cultura náhuatl, destrozada por la conquista.

Se inicia entonces la segunda unidad temática del poema, que denominé provisoriamente, "La transculturación", donde se superponen imágenes de

${ }^{6}$ Es curiosa la " $v^{n}$, quizá como aliteración o también como simple errata. 
diversa procedencia: símbolos judeo-cristianos como la Virgen, el Desollado (¿San Bartolomé?), el Flechado (¿San Sebastián?) y el Crucificado (Cristo) con la "corona de culebras", el colibri ("chispa con alas", que recuerda el calderoniano "ramillete con alas"), resumido en la impertinencia semántica de "tizónflor", la Llama (desde los parsis adorada como divina); La Señora (que puede aludir lo mismo a la Virgen de Guadalupe que a la Coatlicue u otra deidad); la Araña, que tiene múltiple valor semántico y puede relacionarse con las Parcas, pues "hila la luz/hila los días y los siglos" o con la misma Historia; el Conejo (en el Ometochtli, Año del Conejo, llegó Cortés a Tenochtitlán para cumplir la profecía). En la línea 100 se reitera la presencia de Xólotl y cuatro líneas después se introduce la idea de la memoria como "un teatro de piedra", que va así aportando gradualmente nuevos elementos para la comprensión plena del símbolo pétreo manejado por el autor. El fin y destrucción del "kosmos" indígena se resume en el pensamiento "las ideas se comieron a los dioses/los dioses se volvieron ideas" y sobreviene entonces la desintegración: vejigas que revientan, ídolos que estallan, dioses que se pudren, sagrarios convertidos en muladares (líneas 113-118); para dar paso a un estado diferente de cosas: "ideas armadas", "idearios ideodioses", "silogismos afilados" (donde veo una alusión al clero en general y a los teólogos en particular) que degeneran en "perras rabiosas", "caníbales endiosados" e "ideas estúpidas". El sentido de esta segunda división que metodológicamente he realizado creo verlo en el fragmento entre la línea 126 y 151, que abre y cierra con la misma idea, representando simbólicamente un círculo: "Hemos desenterrado la Ira". Aquí se contrasta el pasado con un presente relativo, donde el anfiteatro del sol es un muladar, así como la fuente del agua lunar y el parque de los enamorados. Se produce un tránsito en la historia, pues se pasa a considerar la biblioteca como madriguera de ratas y la universidad como charco de ranas (en alusión quizá de la comedia Las ranas, de Aristófanes), el altar como tramoya de Chanfalla (relacionado con El retablo de las Maravillas, de Cervantes), cerebros manchados de tinta (como posible alusión a la burocracia), doctores y ladrones se identifican por el marco de referencia espacial; "manos rápidas pensamientos duros" son calificativos aplicados a los negociantes, que "ofician en el santuario" como otra posible alusión a los fariseos en el Templo de Jerusalén. Se incuba el huevo de una serpiente que viene marcada por el destino violento: la Ira, alimentada por los dialécticos, la leche dogmática del clero. Todo recuerda la caracterización que hace Valle Inclán del Tirano Banderas y su verde saliva de coca masticada, para producir "imágenes manchadas" por aquellos que "escupieron sobre el origen". Y cierra entonces la mirada apocalíptica con la idea inicial que da paso a la culminación: "Hemos desenterrado a la Ira.

Da comienzo entonces la tercera y última parte del poema "El tiempo de la Ira", con el sentido de fuerza y servidumbre de la preposición inicial; "Sobre el pecho de México" aparecen las "tablas escritas por el sol", quizás vinculadas con las Tablas de la Ley que recibe Moisés en el Monte Sinaí de manos de Jehová; 
la alusión bíblica vuelve a verse en las siguientes líneas, pues al parecer el poeta se refiere a la Torre de Babel, símbolo de la soberbia y confusión de los hombres con pretensiones de igualarse a los dioses: "escalera de los siglos/terraza espiral del viento", o quizás a la Historia, en su desarrollo infinito. "La desenterrada" puede aludir tanto a la muerte pintada por los artistas medievales (El Bosco) como a las calaveras catrinas de José Guadalupe Posada, con "jadeo, sed y rabia" como ansia de aire, agua y violencia; "pelea de ciegos" bajo el mediodía y la referencia recuerda la célebre pintura de Brueghel el Viejo, como símbolo de la irracional discordia entre los hombres que "se golpean con piedras". La piedra llega a ser símbolo trino de estatismo, rigidez y violencia. Todo este fragmento puede aludir tanto a la Guerra Civil, como a la Revolución Mexicana, o a las matanzas de Thatelolco (1968) o de la Normal (1971). La indiferenciación propicia un amplio marco referencial. Hay un signo de violencia (la reiterada piedra petrificada y petrificante) sustancial para la historia mexicana. Y es que la piedra cuenta con una extensa referencialidad bíblica como arma y objeto de la destrucción; con una piedra sacrifica Caín a su hermano Abel, sobre una piedra ata Abraham a su hijo Isaac para el sacrificio, con piedras lapidan a la mujer adúltera en el Nuevo Testamento (impedido por la mano de Cristo que anuncia que sólo pueden hacerlo los que estén limpios de pecado), con piedras es sacrificado el protomártir Esteban .... No es la piedra (petrum) a la que alude el poeta, aquélla sobre la cual se levantaría la institución del perdón (eclesiae). Esla piedra de Huitzilopochtli, la devoradora de corazones humanos desgarrados. El agua del perdón no llega, no brota el manantial de la concordia entre la piedra, que sembrada por el odio, genera más rencor; "se rompen los hombres/ las piedras se rompen/adentro hay un agua que bebemos/agua que amarga/agua que alarga más la sed/¿Dónde está el agua otra?”

El comentario del plano semántico y referencial a que alude la propuesta abierta del texto nos lleva al conjunto de intenciones del poema. La concretización de las imágenes poéticas mediante lo icónico que sucesivamente ofrece el poeta, conduce a una ressemblance afectiva y sugeridora. Existe una linealidad que empieza desde las raíces hasta llegar a lo histórico actual, proyectado mediante la utilización de reiteradas formas verbales en presente. El poeta es el testigo de la Historia y su comentador. Todo gira alrededor del motivo de la piedra, complementado por las connotaciones diversas que asume a través del poema, en un paralelismo confluyente: todo parte de la piedra, todo vuelve a ella. Es la serpiente metafísica mordiéndose la cola. Esta concepción cíclica de la historia marca la intencionalidad del creador, que busca pasar de la subjetividad a la intersubjetividad, a través de los signos (con toda su carga semiótica), hacia una semántica del texto en su pleno e integral significado. Establece para ello un conflicto de interpretaciones que se van repensando, para re-escribir el mundo que expresa el poeta. Paz casi nunca utiliza símbolos hechos ni metáforas gastadas: acude a la potencial impertinencia del lenguaje para elaborar un orbe de implicaciones que constituyen " $\mathrm{su}$ " forma de interpretar el 
mundo de acción, para compartirlo en un diálogo enriquecedor con el lector. Y pone en juego para ello sus mejores recursos, pues tal como ha señalado Monique Lemaître: "En la concepción del poema de Octavio Paz son fundamentales tres elementos: el lenguaje, el ritmo y la imagen"n. A Octavio Paz, lector de Martín Heidegger, no debe resultarle ajeno el mundo de acción de la poesía. No es nada fácil, sin embargo, aplicar con absoluta certeza - por otra parte, ajena a la necesidad esencial del lector de enriquecer su mundo- a una obra como la de Paz cualquier sistema que tienda a cerrar el texto pues, como advierte Lemaitre: "Son los críticos quienes nos ayudan a desentrañar las constantes y las variables dispersas en escritos que pertenecen a épocas diferentes y modalidades distintas. En el caso de Octavio Paz la tarea resulta a un tiempo más fácil y más difícil. Más fácil porque su poética coincide perfectamente con el sentido de sus poemas. Más difícil porque la misma lucidez del poeta vuelve más arduo el camino del análisis crítico"8. El propio Paz lo ha advertido, cuando en Corriente alterna señala que "todo lo que nombramos ingresa al círculo del lenguaje $y$, en consecuencia, a la significación. El mundo es un orbe de significados, un lenguaje. Pero cada palabra posee un significado propio, distinto y contrartio al de las otras palabras. En el interior del lenguaje los significados se combaten entre sí, se neutralizan y se aniquilan. La proposición: todo es significativo porque todo lenguaje puede invertirse: todo carece de significación porque todo es lenguaje ${ }^{\prime 9}$. El destino incierto y por tanto infinito del poema, lo reitera Paz en Puntos de partida: "Palabras, ganancias de un cuarto de hora arrancado al árbol calcinado del lenguaje, entre los buenos días y las buenas noches, puertas de entrada y salida y entrada de un corredor que va de ninguna-parte a ningúnlado"10.

Esta importancia de la palabra en la obra de Paz no es el resultado de una casualidad, sino de un meditado proceso de selección y valoración, al cual alude numerosas veces el poeta, como una de sus obsesiones fundamentales; el Poeta, en tanto Dueño de la Palabra, es semejante al Creador de un mundo: "Invento la víspera, la noche, el día siguiente que se levanta en su lecho de piedra y recorre con ojos límpidos un mundo penosamente soñado. Sostengo al árbol, a la nube, a la roca, al mar, presentimiento de dicha, invenciones que desfallecen y vacilan frente a la luz que disgrega .... Allá, donde los caminos se borran, donde acaba el silencio, invento la desesperación, la mente que me concibe, la mano que me dibuja, el ojo que me descubre. Invento al amigo que me inventa, mi semejante; a la mujer, mi contrario: torre que corono de banderas, muralla que escalan mis espumas, ciudad desvastada que renace lentamente bajo la dominación de mis

\footnotetext{
${ }^{7}$ Monique Lemaître, Octavio Paz: Poesíay Poética, México: UNAM, 1976, 11. En adelante se citará como Lemaître

${ }^{8}$ Lemaitre, 116.

${ }^{9}$ Octavio Paz, Corriente alterna, México: Siglo XXI, 1967, p. 8 Apud. Lemaître, 13.

${ }^{10}$ Octavio Paz, "Puntos de partida",Apud. Jorge Rodriguez Calderón, Octavio Paz, Madrid: Jucar, 1975, 172. De ahora en adelante se citará como Rodríguez Calderón.
} 
ojos .... Contra el silencio y el bullicio invento la Palabra, libertad que se inventa y me inventa cada día .... ${ }^{\prime 11}$. El vínculo de reciprocidad entre la palabra y quien la crea, aumenta en progresión permanente el universo del autor-lector creador. Por ello, Lemaître ha señalado que "de acuerdo con las ideas de Octavio Paz, la palabra es un elemento vivo que forma parte del hombre. Un elemento cuya vida y muerte dependen del hombre. Si lo que distingue al hombre de los animales y de las plantas es su facultad de utilizar símbolos conscientemente, la palabra por su parte sólo tiene sentido en relación al hombre ${ }^{12}$. La acción de esta palabra abierta en Paz es el disfrute poético, la cual resume Magis al decir que "es preciso experimentar en nosotros mismos cómo se ensancha el imponderable placer estético que provoca el mensaje lírico del poeta al percibir que vamos penetrando naturalmente en los niveles más profundos de sus incitantes revelaciones gracias a un lenguaje eufórico, secreto y violento"13. Es la constante apertura del texto, infinito en sus posibilidades de lecturas, que Paz asume al proponer una revisión constante de su obra, para coincidir así con Jorge Luis Borges, quien postuló que "el concepto del texto definitivo sólo corresponde a la religión o al cansancio"14. Esto apoya el criterio de Lemaitre cuando señala que "la poética de Paz no es, como la de Boileau, preceptiva ${ }^{15}$. Se trata de una apertura constante a la interpretación enriquecida por la referencialidad escindida del propio texto y de las circunstancias del lector. Esta relativa imprecisión del hecho literario no es una limitante, sino un valor de comunicación múltiple y válido, pues "si la literatura es expresión, está condenada a la complejidad y a la ambigüedad. En literatura no hay verdades simples, y cada obra contiene su negación, su crítica. Esto es lo que distingue a la literatura moderna de la antigua. Quizá Homero sea simple, pero Cervantes es complejo, problemático, ambiguo", señala $\mathrm{Paz}^{16}$. A partir de lo ambiguo y complejo se llega a la noción del azar y lo casual ("el azar concurrente", lo llamaba José Lezama Lima) que identifica a Paz con Marcel Duchamp: "Su fascinación ante el lenguaje es de origen intelectual: es el instrumento más perfecto para producir significados $\mathrm{y}$, asimismo, para destruirlos. El juego de palabras es un mecanismo maravilloso, porque en una misma frase exaltamos los poderes de significación del lenguaje, sólo para, un instante después, abolirlos más completamente ... el espíritu solitario se enfrentará al absoluto y su máscara: el azar ${ }^{\text {117 }}$.

El tiempo es preocupación constante de la poesía de Octavio $\mathrm{Paz}$, como curso y meta, según lo ha visto Carlos Fuentes: "La obra literaria que, al arrêter du

\footnotetext{
11 Octavio Paz, Libertad bajo palabra. Apud. Rodriguez Calderon, 165-166.

12 Lemaître, 12-13.

${ }^{13}$ Carlos H. Magis, La poesía hermética de Octavio Paz. México: El Colegio de México, 1978, 2.

14 Jorge Luis Borges, Apud. Magis, 4.

${ }^{16}$ Lemaitre, 5.

16 Octavio Paz, Sólo a dos voces (Conversaciones con Julián Ríos), Barcelona, 1973, 15

${ }^{17}$ Octavio Paz, Marcel Duchamp o el Castillo de la Pureza, Mexico: Era, 1968, 274.
} 
jour se instala en el presente sólo para recordar el origen del ser imaginado en la meta"18. Esto, aplicado al lenguaje mismo, explica lo que señala Paz cuando en El mono gramático declara que "la fijeza es siempre momentánea. ¿Cómo puede serlosiempre?... Las relaciones entre la retóricay la moral son inquietantes: es turbadora la facilidad con que el lenguaje se tuerce y no lo es menos que nuestro espíritu acepte tan dócilmente esos juegos perversos. Deberíamos someter el lenguaje a un régimen de pan y agua, si queremos que no se corrompa y nos corrompa (lo malo que régimen-de-pan-y-agua es una expresión figurada como lo es la-corrupción-del-lenguaje-y-sus-contagios). Hay que destejer (otra metáfora) inclusive las frases más simples para averiguar qué es lo que encierran (más expresiones figuradas) y de qué y cómo están hechas (¿de qué está hecho el lenguaje?) y, sobre todo, ¿está hecho o es algo que perpetuamente se está haciendo?). Destejer el tejido verbal: la realidad aparecerá ...."19 Esta irónica observación de $\mathrm{Paz}$ pone en evidencia algo que la hermenéutica fenomenológica demuestra: vivimos en un mundo de metáforas y la base del lenguaje poético está en la propia esencia del lenguaje como asociación de posibles e infinitos significados, lo cual ilumina toda la concepción de su obra, que une coherentemente la labor "pura" de creación y la reflexión, pues, como ha apuntado atinadamente Saúl Yurkievich: "Los dos poetas en lengua castellana que mejor ejemplifican la correspondencia entre el sistema de representación y la concepción del mundo contemporáneo son, según creo, César Vallejo y Octavio paz. En Octavio Paz esta reciprocidad es aún más explicita que en Vallejo, porque el pensamiento metafórico, el mito, va siempre de la mano de la teoría"20.

Laimportancia del diálogo en la concepción del texto poético es fundamental en Octavio Paz, pues, "si se parte de la base de que todo para Octavio Paz, en la historia, es diálogo entre el hombre y el mundo, y si lo que se necesita es clasificar la forma en que se establece y mantiene este diálogo; es decir, la significación del discurso y las posibles variaciones que la misma puede experimentar a través de la historia, llegamos a encontrarnos con la crítica de la propia historia, de los diferentes aspectos del tiempo, a los que nuestro escritor caracteriza de forma muy luminosa y particular. Quizá sea su teoría del tiempo, y de la influencia de su diversa aceptación en la obra literaria (en el lenguaje), la más singular de cuantas especulaciones habitan en el seno de su obra .... Para Octavio Paz el mundo no es un todo cerrado, sino que se presenta comola resultante de una serie de fuerzas múltiples, de perspectivas diferentes, que reclaman su protagonismo, pero no de forma individualizada, sino como

\footnotetext{
${ }^{18}$ Carlos Fuentes, "El tiempo de Octavio Paz". Prólogo a la edición española de Los signos en rotación, Madrid: Alianza Editorial, 1971. Apud. Rodriguez Calderón, 56.

${ }^{10}$ Rodríguez Calder6n, 211-12.

${ }^{20}$ Saúl Yurkievich, Fundadores de la nueva poesta latinoamericana, Barcelona: Seix Barral, 1971, 203.
} 
elementos de esa totalidad"21. Todo lo cual creo que se sintetiza ejemplarmente en su visión de "Petrificada petrificante".

Pero eso, se me hace difícil aceptar en todo y al pie de la letra la valoración de Lemaitre ${ }^{22}$ sobre la actitud de Paz ante el azar, quien lo asume como reto en su rica multiplicidad, lejos de considerarlo como una barrera. Lo cierto es que hay preocupaciones constantes, "obsesiones" reitero, en la poesía de Paz: una de ellas, creo que muy importante, es la noción del tiempo y de la historia. El poeta asume su circunstancia, pues el presente tiene sus raíces en el pasado y sus ramas en el futuro. Estamos abrazados a un tronco con dibujos caprichosos en apariencia, pero con justificaciones "fatales" en la historia. "Petrificada petrificante" es una muestra ejemplar de esta obsesión pero no la única. La referencialidad en la producción de un creador también está relacionada con su propia obra en conjunto. Hay notas en ellas que avisan o desarrollan el tema de "Petrificada petrificante" y la iluminan, por ejemplo la insistencia sobre el motivo de la piedra, en el "Nocturno de San Idelfonso":

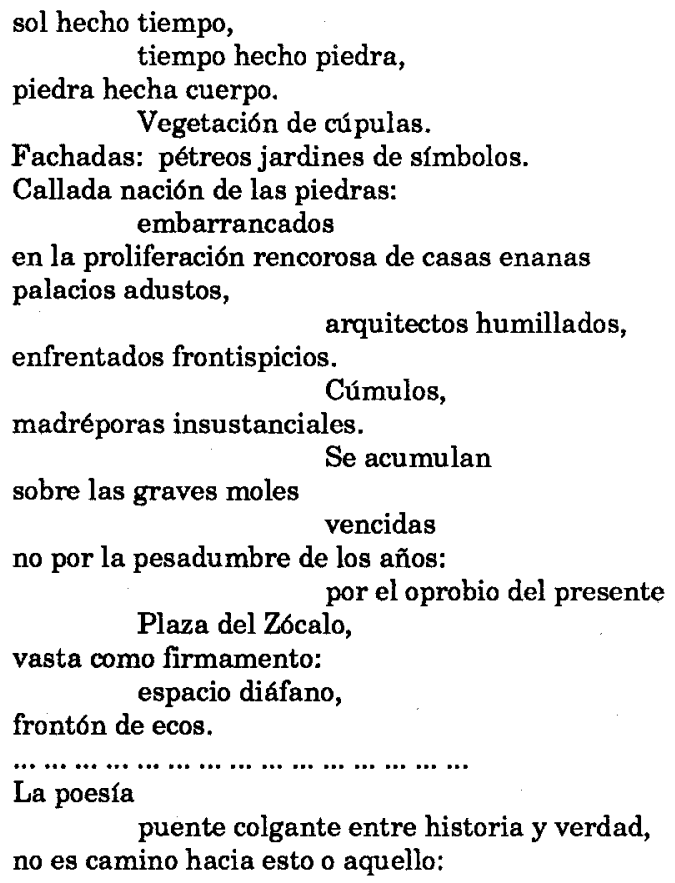

${ }^{21}$ Rodriguez Calderón, 54-55.

${ }^{22}$ Lemaitre, 115. 


\section{es ver}

la quietud en el movimiento

el tránsito en la quietud.

La historia es el camino:

no va a ninguna parte.

Todos lo caminamos:

la verdad es caminarlo.

No vamos ni venimos:

estamos suspendidos

en las manos del tiempo.

La verdad es sabernos,

desde el origen, suspendidos:

fraternidad sobre el vacío.

En el poema "Vuelta", que pertenece al libro homónimo, Paz resume su situación vivencial, angustia asfixiante ante la violencia que lo rodea, que también reflejara "históricamente" en "Petrificada petrificante":

\begin{tabular}{|c|c|}
\hline \multicolumn{2}{|l|}{ (n) } \\
\hline \multicolumn{2}{|l|}{ sin avanzar } \\
\hline \multicolumn{2}{|l|}{ de ciudad } \\
\hline \multirow{2}{*}{ me falta cuerpo } & Mediodía \\
\hline & $\begin{array}{l}\text { puño de luz } \\
\text { que golpea y golpea }\end{array}$ \\
\hline 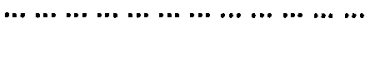 & He vuelto \\
\hline воге & ¿gané o perdí? \\
\hline
\end{tabular}

El autor insiste en el motivo clave de la piedra en su poema "Himno entre ruinas", de estrecha relación también con "Petrificada petrificante".

En "Piedra de sol", verdadera "Ars poética" de Paz" ${ }^{23}$, el poeta insiste en su noción del decursar como flujo ascendente que ilumina las acciones de los hombres y la historia. El sentido de la palabra es motivo recurrente en Paz. Lemaître lo cita comentándolo: "Las palabras no son las cosas; son los puentes que tendemos entre ellas y nosotros' .... Paz no niega que todo lo que nos rodea pertenezca a un tipo u otro de lenguaje pero, y de acuerdo con la teoria de Ernst Cassirer, subraya la necesidad de un intérprete, o sea de un hombre capaz de

${ }^{23}$ Vid. Mario J. Valdés, Phenomenological Hermeneutics and the study of Literature, Canada: University of Toronto Press, 1987, 91-103. 
traducir los signos que lo rodean. Un sistema de comunicación no es sinónimo de lenguaje"24. Esta "lucha" con la palabra se traduce en su poema "Las Palabras":

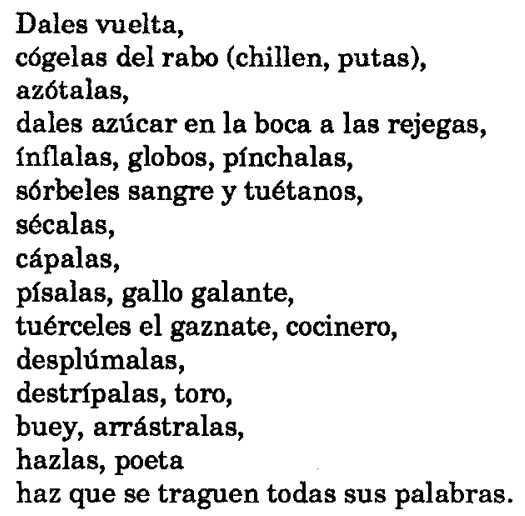

$E$ insiste sobre ésto en otros dos poemas:

"La palabra dicha"

La palabra se levanta

de la página escrita.

La palabra,

labrada estalactita, grabada columna une a una letra a otra letra

El eco se congela

En la página pétrea

"La palabra escrita"

Ya escrita la primera

palabra (nunca la pensada

sino la otra-ésta

que no la dice, que la contradice,

que sin decirla está diciéndolo)

El valor del diálogo enriquecedor se aprecia también en la obra general de Paz, pues aún sintiendo el lenguaje de la poesía como un balbuceo, experimenta

24 Octavio Paz, Fernando Pessoa, Mexico: UNAM, 1962, 26. Apud. Lemaitre, 11-12. 
"la necesidad de compartir con alguien el placer de descubrir un mundo nuevo en cada poema y la experiencia, a veces amarga, de habitar esos mundos ${ }^{225}$. La lucha del poeta con su circunstancia, heridora y permanente, se traduce en una tarea de Sísifo inacabable, que busca en el lector compartir la angustia de ese peso: "Avanzo, perforo grandes rocas de años, grandes masas de luz compacta, desciendo galerías de minas de arena, atravieso corredores que se cierran como labios de granito. Y vuelvo al llano, al llano donde siempre es mediodía, donde un sol idéntico cae fijamente sobre un paisaje detenido. Y no acaban de caer las doce campanadas, ni de zumbar las moscas, ni de estallar en astillas este minuto que no pasa, que sólo arde y no pasa" ${ }^{26}$. Es así como se asume una situación de ruptura, de desgarramiento y toma de conciencia, que marca el instante de creación de "Petrificada petrificante": "Tras el reconocimiento de la crisis del diálogo, y la urgencia por encontrar un lenguaje no confundidor, que sea palabra pura y original, y tras el encuentro con la culminación del orden armónico de las analogías en el acto erótico (fusión del tiempo instantáneo y del espacio puro; fusión de contrarios en una totalidad equilibrada de fuerzas que se buscan e interrogan)", Octavio Paz llega a la convicción del poema" como lugar, como ámbito de esa confluencia, y a convencerse igualmente de que los signos son los verdaderos protagonistas del poema. No existe una sola lectura del mundo en la escritura poética, sino una conversión del mismo en un espacio y tiempo diferentes, espacio y tiempo donde lo esotérico y analógico sirven de apoyos para su configuración ${ }^{\text {"27 }}$.

"Petrificada petrificante" es pues, un testimonio del cambioen lainmovilidad, fijado con un destino fatal, que responde a la esencia misma de la historia; poema iracundo donde "una sensación de ira se desprende además de este monumento pétreo, geológico, prehispánico, mexicano y universal que son los poemas de 'Petrificada petrificante'. 'Hemos desenterrado la ira', nos dice en uno de los poemas que es una afilada diatriba en contra del mundo 'civilizado' y de sus dogmas; así como una denuncia ecológico-poética del legado del hombre del siglo XIX ${ }^{28}$.

Poema de valoración histórica al mismo tiempo que de palpitante y urgente actualidad, "Petrificada petrificante" es obra de creación y de análisis. Paz se encuentra continuamente reescribiendo su obra, manteniéndola abierta a las mutaciones, negando su fosilización. El tiempo no pasa, nosotros pasamos a través de él; por tanto no hay una Historia, sino la que a diario escribimos en su enorme multiplicidad. El gran motivo de "Petrificada petrificante", el Valle de México y la Ciudad de México-Tenochtitlán, se muestra a partir del comentario hermenéutico en su rica diversidad de acepciones y sentidos, enriqueciendo al

\footnotetext{
${ }^{25}$ Magis, 5.

${ }^{26}$ Octavio Paz, "Llano", Apud. Rodríguez Calderón, 172.

${ }^{27}$ Rodriguez Calderon, 129.

${ }^{28}$ Lemaitre, 146.
} 
lector que soy: después de esta lectura "peligrosa" (la poesía es quizá el más riesgoso salto al vacío de la imaginación), mi noción del mundo mexicano se enriquece, no atado a conceptos preestablecidos, sino a través del diálogo con el poema, pues "his basic argument is that literary texts are inexhaustible resources of imaginative creativity for their readers, and, further, that this openness does not inhibit serious commentary but rather enhances the critic's possibilities of exchanges, dialogue, and intelectual enrichment ${ }^{\text {229 }}$.

${ }^{29}$ Mario J. Valdés, Shadows in the Cave: A Phenomenological approach to Literary Criticism Based on Hispanic Texts, Toronto: University of Toronto Press, 1982, 215. 
